\title{
Demiryolu Ulaşım Güvenliği için Makinist Uyarım Sistemi Kavramsal Tasarımı ve Simülasyonu
}

\author{
Harun SÜMBÜL ${ }^{* 1} \oplus$, Ahmet BÖĞREK²®, Abdurrahman TUNÇER ${ }^{1}(0$ \\ ${ }^{1}$ Ondokuz Mayıs Üniversitesi, Yeşilyurt Demir Çelik MYO, Elektronik ve Otomasyon Bölümü, Samsun, \\ Türkiye \\ ${ }^{2}$ Ondokuz Mayıs Üniversitesi, Yeşilyurt Demir Çelik MYO, Motorlu Araçlar ve Ulaştırma Teknolojileri \\ Bölümü, Samsun, Türkiye \\ *harun.sumbul@omu.edu.tr
}

(Alınış/Received: 26.11.2020, Kabul/Accepted: 27.01.2021, Yayımlama/Published: 31.07.2021)

\begin{abstract}
Öz: Bu çalışmada, demiryollarında güvenli yolculuk için deray anını tespit ederek makiniste bilgi veren bir sistemin kavramsal tasarımı gerçekleştirilmiş olup sistem aynı zamanda bir bilgisayar programı ile simüle edilmiştir. Buna göre bir elektronik devre çizim programı (Proteus ISIS Labcenter Electronics 7.7 SP2) yardımı ile kavramsal tasarıma ait bir devre çizilmiştir. Devre üzerinde, treni temsilen sinyal üreteci; titreşimlerin ve kapasitif değerlerin algılandığını temsil eden butonlar, alınan sinyallerin yükseltildiği opamplı yükselteç devresi, iki algılayıcıdan da alınan verilere göre makiniste bilgi gönderilmesine karar verecek olan bir karşılaştırıcı (VE kapısı), sinyallerin izlendiği dijital osiloskop ve deray algılandığında makinist uyarımında kullanılacak sesli/1şıklı uyarım sistemi (buzzer) bulunmaktadır. Demiryolu titreşimleri ve oluşan frekans aralıkları için ilgili literatür göz önüne alınarak simülasyon devresinde sinyal üreteci frekansı $1,5 \mathrm{KHz}$ ve genliği ise $5 \mathrm{v}$ üçgen dalga DC şeklinde ayarlanmıştır. Eşik değer olarak $2.5 \mathrm{v}$ seçilmiştir. Buna göre karşılaştırıcı çıkışındaki değer, her iki algılayıcıdan da bilgi alındığı anda aktif olmuştur. Simülasyona göre deray $300 \mathrm{~ms}$ sürmüş ve $1 / 3$ saniye gibi kısa bir sürede tespit edilerek çıkış birimleri aktif edilmiştir. Simülasyon sonuçlarına göre önerilen kavramsal modelin gerçek hayatta başarılı bir şekilde kullanılabileceği ve böylece deray kaynaklı tren kazalarının önüne geçebileceği öngörülmüştür. Bunun neticesi olarak da ölümlü / yaralanmalı / maddi kayıplı kazaları engellenerek ülkemize tren ile güven ile ulaşım konusunda yeni bir literatür kazandırılacağına inanılmaktadır.
\end{abstract}

Anahtar kelimeler: Demiryolu, Deray, Vagon, Haberleşme, Kontrol Sistemleri, Mikrodenetleyici

\section{Conceptual Design and Simulation of Railway Machinist Excitation System for Transportation Safety}

Abstract: In this study, a conceptual design of a system that provides information to the mechanic by detecting the derailment moment for safe travel in railways has been realized and the system has also been simulated via a computer program. Accordingly, a circuit belonging to the conceptual design was drawn with the help of an electronic circuit drawing program (Proteus ISIS, Labcenter Electronics 7.7 SP2). The signal generator representing the train on the circuit; the buttons representing the detection of vibrations and capacitive values, the opamp amplifier circuit in which the received signals are amplified, a comparator (AND gate) that will decide to send information to the machine according to the data received from both sensors, the digital oscilloscope where the signals are monitored and the audible / light stimulation system to be used in the mechanic warning when the derails are detected are available. Considering the relevant literature for railway vibrations and the frequency ranges that occur, the signal generator frequency in the simulation circuit was set as $1.5 \mathrm{KHz}$ and the amplitude as $5 \mathrm{v}$ triangle wave DC. Accordingly, the value at the comparator output became active when the information was received from both sensors. According to the simulation, derilment lasted $300 \mathrm{~ms}$ and was detected in a short time like $1 / 3$ second and the output units were activated. According to the simulation results, it was predicted that the proposed conceptual model could be used successfully in real life, thus preventing train accidents caused by deray. As a result of this, it is believed that a new literature will be brought to our country on safe transportation by train by preventing accidents with death / injury / financial loss. 
Keywords: Railway, Derailment, Wagon, Communication, Control, Microcontroller

\section{Giriş}

Dünya nüfusundaki artış ve iletişim ihtiyaçları; ulaşım konusunda da daha geniş bir bakış açısı ve yeni teknolojik ihtiyaçlar gerektirmiştir. Nitekim gelişmiş ülkeler son dönemde daha fazla ekonomiklik, bir takım çevresel sorunlar ve küresel iklim değişikliği nedenleriyle çevre dostu taşımacılık türlerinden olan demiryolu payının arttırılmasına ve seyrüsefer güvenliğine yönelik politikalar üretmekte ve uygulamaktadır.

Ülkemiz demiryolu ile ulaşım konusunda özellikle son dönemde ciddi yatırımlarda bulunmuştur (2002 yılında ulaştırma sektörleri içerisinde demiryolunun yatırım payı \%10 iken 2018 yılında \%49 olmuştur). Ülkemizde mevcut tren yolu hat uzunluğu 2010 yılında $(8.686$ km'si konvansiyonel ana hat, $2.322 \mathrm{~km}$ 'si tali hat ve $397 \mathrm{~km}$ 'de yüksek hızlı tren hattı olmak üzere toplam) $11.405 \mathrm{~km}$ iken 2017 Eylül istatistiklerine göre bu rakam $12.532 \mathrm{~km}$ 'ye ulaşmıştır [1]. 2023 yilı hedefleri arasında ek 10 bin km tren yolu yapımı, yüksek hızlı tren (YHT) ve 4 bin km konvansiyonel hat yapılması, tüm hatlardaki dingil basıncının 22,5 tona çıkarılması, demiryolu işletmeciliğinde özel sektör payının yüzde 50'ye çıkarılması, 4.400 km'lik hat yenilemesi yapılarak tüm hatların yenilenmesi, demiryolu taşımacılık payının; yolcuda $\% 10$ ve yükte $\% 15$ 'e çıkarılması gibi önemli hedefler de bulunmaktadır. Ayrıca 11.Kalkınma Planında yer alan demiryolu sektör hedefleri içerisinde trafik yoğunluğuna bağlı olarak belirlenen öncelik sırasına göre mevcut tek hatlı demiryollarının çift hatlı hale getirilmesi ve şebekenin ihtiyaç duyduğu sinyalizasyon ve elektrifikasyon yatırımlarının hızlandırılması şeklinde önemli hedefler bulunmaktadır. Bunun yanında ülkemizde ulaşım sistemi, hem salt ulaştırma teknolojisindeki hem de elektronik ve bilişim teknolojisindeki çok hızlı gelişmelerin etkisiyle, ciddi yapısal değişikliklerin eşiğinde bulunmaktadır [2]. Türkiye Cumhuriyeti Devlet Demiryolları (TCDD) işletmesi genel müdürlüğü, AR-GE Daire Başkanlığı tarafindan yayımlanan Emniyet Yönetim Sistemi El Kitabında mevcut emniyet anlayışı ve sistemine ilave olarak $\mathrm{AB}$ ülkelerinde ve dünyanın gelişmiş ülkelerinde uygulanmaya başlanan ve kullanılmakta olan düzenlemelere dayanan Emniyet Yönetim Sistemini hayata geçirmektedir [3]. Görüldügü gibi tren yolları taşımacıllğı ve güvenliği oldukça önem kazanmış ve hatta devlet politikası haline gelmiş durumdadır.

Ülkemiz demiryolu ile ulaşım konusunda yapılan yatırımlarla oldukça ileri seviyeleri yakalamış olmasına rağmen raylı sistem araçlarının ve bileşenlerinin test edilmesinde kolaylık sağlayan ekipmanlarından ray simülatörleri kullanma, tren, ray bakımı ve seyrüsefer güvenliği gibi konularda teknolojinin oldukça gerisinde kalmıştır [4]. Zira TCDD işletmesi genel müdürlügünün 2009 yılı sektör raporuna göre mevcut dizelli lokomotiflerin $\% 65$ 'i, elektrikli lokomotiflerin \%63'ü, yolcu vagonlarının \% 55'i, yük vagonlarının \%60'1 20 yaşın üzerindedir [5]. Dolayısıyla tren ve raylardaki bakımsızlık ve buna bağlı meydana gelen kazalar, yapılan bunca yatırımı gölgede bırakabilmektedir. Uluslararası Demiryolları Birliği (UIC) standartlarına göre kazalar: işletmeye ait ana hatlarda veya tali hatlarda gerek hat boyunda gerekse garlarda işletmeye ait demiryolu araçlarının karıştığı durumları içermektedir. Buna göre kazalar; tren çarpışması, deray, trenden düşme ve diğer kazalar (trenin şahsa çarpması, geçit çarpışması, yangın vb.) şeklinde kategorize edilmektedir.

Trenler, vagonların uzunluğuna bağlı olarak yapıları gereği yüzlerce parçadan oluştuklarından ağır ve kontrolü zor olan araçlardır. Özellikle yük vagonlarının seyir sırasında raylar üzerinde olup olmadığının kontrolü hayati öneme sahiptir. Seyrüsefer esnasında trenin en az bir tekerleğinin rayları terk etmesi olayı Deray olarak tanımlanmaktadır [6]. Şekil 1'de deray sonucu yan yatmış bir tren görülmektedir. 


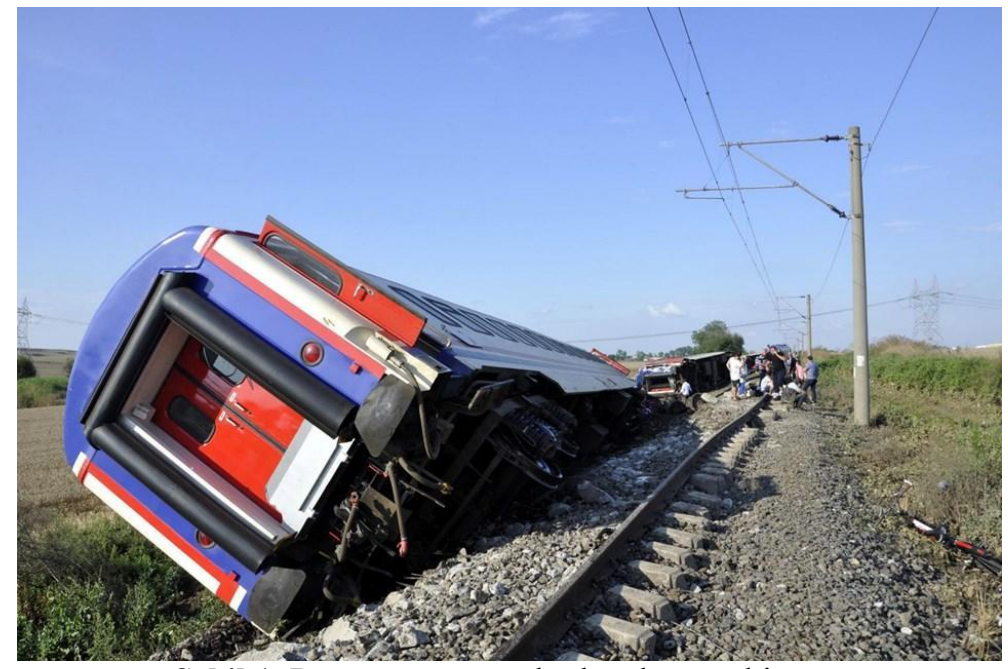

Şekil 1. Deray sonrası raylardan düşmüş bir tren

En önemli kaza sebebi olan deray öncesi seyrüsefer sırasında demiryolu hattındaki bozulmaların bulunduğu yerlerde vagonlar hat üzerinde değişik yönlerde (aşağı/yukarı, sağa/sola) hareket etmeye başlar. Hareketler, raylardaki bozulma şekline bağlı olarak değişiklik gösterir. Geniş bir açıklıktaki hat bozulmalarında görülen değişmeler, düşey ve yatay gövde titreşimlerine ve gürültüye sebep olur. Böylece yolcular tren hızına bağlı olarak oluşan dengelenmemiş merkezkaç kuvvetinin etkisiyle kurp dışına doğru savrulur. Büyük bir reaksiyon kuvvetinin raylara etkimesiyle vagon kurp boyunca devrilir ve tren raydan çıkabilir [7]. Böylece vagon metrelerce sürüklenebilmektedir. Sürüklenme esnasında vagon tamamen raydan ayrılıp bağlı olduğu diğer vagonların da sürüklenmesine hatta devrilmesine de sebep olabilmektedir. Bu olay neticesinde tren yolundaki traversler hasar görmekte, vagonların raylar üzerinden kaldırılması süresince yol trafiğe kapalı kalmakta ve buna bağlı olarak bir sonraki yolcu treni saatlerce bekletilebilmekte ve ağır maddi manevi kayıplar verilebilmektedir. 2012-2016 yıllarına ülkemizde meydana gelen kaza sebepleri ve kaza sayıları Tablo 1'de görüldüğü gibidir [8].

Tablo 1. 2012-2016 yıllarında meydana gelen kaza sebepleri ve kaza sayıları

\begin{tabular}{cccccc}
\hline \multirow{2}{*}{ Kaza Sebebi } & \multicolumn{5}{c}{ Yillara Göre Kaza Sayıları } \\
\cline { 2 - 6 } & 2012 & 2013 & 2014 & 2015 & 2016 \\
\hline Tren Çarpışması & 4 & 2 & 2 & 4 & 6 \\
Deray & 32 & 22 & 10 & 28 & 23 \\
Trenden Düşme & 13 & 2 & 3 & 2 & 2 \\
Diğer Kazalar & 9 & 1 & 3 & 6 & 4 \\
TOPLAM & 58 & 27 & 18 & 40 & 35 \\
\hline
\end{tabular}

2007-2012 yılları arasında yukarıda bahsedilen sebeplerde dâhil ülkemizde demiryolu kazaları nedeni ile toplam 503 kişi hayatını kaybetmiştir. 2007-2012 yılları arasında Türkiye'de 242.339.000 tren.km taşımacılık yapılmıştır (literatürde ölçek olarak tren.km kullanılmaktadır). Buna göre 2007-2012 yılları için tren.km olarak Türkiye'deki ölüm miktarı 2,08 olarak kayda geçmiştir. $\mathrm{Bu}$ değer tüm $\mathrm{AB}$ ülkelerininkinden büyüktür. Türkiye'yi; Litvanya, Polonya, Romanya, Estonya, Slovakya, Letonya izlemektedir. En düşük değerler ise sırasıyla İngiltere, Hollanda, Norveç, İrlanda, Fransa, Danimarka, Almanya, İsveç, Portekiz'e aittir. En düşük oran 0,16 değeri ile Avusturalya, 0,32 değeri ile Avrupa Birliğine aittir. Türkiye haricindeki ülkeler için ortalama değer 0,43 dür. Dünyanın en uzun demir yoluna sahip olan (yaklaşık $250.000 \mathrm{~km}$ ) ABD için ise bu sayı 0,63'dür.Türkiye'de 2008-2012 yılları toplamı için dünya ortalamasının yaklaşık beş katı ölüm vakası meydana geldiği anlaşılmaktadır [9]. Ayrıca 2010-2012 yıllarında 
$A B$ ve Türkiye'de nedenlerine göre ciddi kaza oranları incelendiğinde; $A B$ de deray sebebi ile meydana gelen kaza oran $1 \% 4$ iken ülkemizde bu rakam \%26'dır. Tüm dünyada deray, tren kaza sebeplerinin başında gelmektedir. Ulaştırma denizcilik ve haberleşme bakanlığı, kaza araştırma ve inceleme kurulu, 2017 yılı demiryolu kaza istatistikleri raporuna göre insan kaynaklı hatalar sonucu oluşan derayın arttığını vurgulanmaktadır [10].

Deraydan kaynakların kaza oranlarındaki artışlara daha eski yıllara göre bakıldığında ise 2003 yılında kaza sayısı 90 iken 2004 yılında 115 olmuş ve en fazla artış (\%27,7) oranı bu iki yıl arasında olmuştur. Deray sebebi ile gerçekleşen kazalarda azalma oranı ise en fazla 2011 yılı ile 2012 yılları arasındadır. 2011 yılında kaza sayıs1 51 iken 2012'de 32'ye düşmüştür. Deray sebebi ile Türkiye'de meydana gelen tren kazaların toplam sayısı 1141' dir. Bu kazaların 54'ü ölümle, 248'i yaralanmayla sonuçlanmıştır [11]. Deray kaynaklı kazalarının önlenmesi büyük önem taşımaktadır. Zira bunun en son ve en acı örneği 8 Temmuz 2018 tarihinde Tekirdağ'ın Çorlu ilçesinde gerçekleşen, Kapıkule-İstanbul seferini yapan trenin deray sonucu 5 vagonunun devrilmesi neticesinde 24 yolcunun ölmesi 318 yolcunun yaralanması ile sonuçlanan tren kazasidır.

Tren kazalarının nedenlerinin araştırılması için ülkemizde 06 Mayıs 2013 tarihinde TCDD tarafından Kaza Araştırma ve İnceleme Kurulu kurulmuş ve meydana gelen kazalar bu kurul tarafından kategorize edilerek yaklaşık 150 çeşit kaza sebebini içeren bir istatistik çıkarılmıştır. $\mathrm{Bu}$ kurul kazalar hakkında ayrıntılı raporlar düzenlemektedir $[12,13]$. İstatistiksel veriler ve yapılan tren kazaları nedenleri araştırma raporları durumun ne kadar önemli olduğunu gözler önüne sermektedir. Bu yüzden özellikle deray kaynaklı kazaların en aza indirilebilmesi için yeni teknolojik çözümler üretilmesi gerekmektedir.

Deraya nelerin sebep olduğu konusu oldukça karmaşık bir durum olmakla birlikte deraya neden olabilecek parametreler literatürde ayrıntılı bir şekilde açıklanmıştır [14-17]. Bu durumların herhangi birisi meydana geldiğinde araç atalet kuvvetleri etkisinde kalarak rayların dışına çıkmaya zorlanır ve raylardan çıkar.

Mevcut durumda vagonlarda bulunan frenleme sistemi lokomotifte bulunan makinist tarafindan tetiklenir. Fren pabuçları havanın kesilmesiyle tekerlekleri kavrayarak frenlemeyi sağlar. Makinistler deray olayını, vagonlardan birine ait hava hortumlarının kopmasıyla oluşan frenleme sonucunda tren hizında meydana gelen yavaşlamadan anlayabilmektedirler. Bu uygun olmayan, ilkel, oldukça güvensiz, yüksek riskli, yavaş ve tehlikeli bir tespit yöntemidir. Hızla ilerleyen bir trende derayın bu şekilde tespit ediliyor olması, tedbir için zaman kaybına ve böylelikle telafisi mümkün olmayan sonuçlarla karşılaşılmasına sebep olmaktadır [18]. Bu sebeple deray anında oluşacak hasarları en aza indirmek amacıyla deray anında makinist tarafından bu durumun anında fark edilmesini sağlamaya yönelik bir sistemin gerçekleştirilmesi tren yolu taşımacılığında (gerek yük gerekse de yolcu taşımacılığında) hayati öneme sahiptir.

Buna paralel olarak demiryolu hizmetlerinin gün geçtikçe büyüdüğü göz önüne alındığında dünyada 2005-2050 yılları arasında demiryolu yük taşımacılığında \%80, yolcu taşımacılığında ise \%51'lik bir büyüme olması öngörülmektedir. Bu durum, diğer yandan demiryollarında oluşabilecek risklerin de artması anlamına gelir. Polonya, Belçika ve Portekiz'de demiryollarının güvenliğini artırmak için yürütülen Avrupa Birliği Araştırma Projeleriyle, demiryolu ve vagon bakımının maliyeti düşürmek ve olası kazaları önlemeyi düşünmektedir. $\mathrm{Bu}$ amaçla trenlerin ses ve titreşimleri üzerinden durum analizini yapabilecek bir gözlem sistemi geliştirilmiştir [19]. Fakat bu çalışma daha çok kavşak kontrolü ve hemzemin geçit kazaları üzerine yoğunlaşmaktadır.

Benzer şekilde demiryolu emniyetli ulaşım konusunda Aydemir B., Akgül Y. ve Tolay E. vagonların yük ve güvenlik durumlarının belirlenmesi için traverslere kuvvet ölçme cihazları 
monte ederek seyir halindeki trende deray olma olayını incelemişlerdir [20]. Yolda bulunan binlerce travers incelendiğinde her traverse bu sistem monte edilemeyeceğinden sistemin yetersiz kaldığı ve iki ölçüm noktası arasında derayın olması durumda ise sistemin kullanılamayacağı açıkça görülmektedir.

Gülşah Karaduman, Mehmet Karaköse ve Erhan Akın raylardaki arızaları teşhis etmek için temassız bir yöntem önermektedir. Bir CCD kamera ve bir lazer tarayıcı içeren özel bir yazılımla birleştirilmiş lazer tarayıcılı kamera kullanılarak üç boyutlu ray görüntüsü elde edilmektedir. Elde edilen görüntüler görüntü işleme teknikleri ile işlenerek ray profili elde edilmekte ve raydaki arızalar tespit edilmektedir [21]. Fakat bu çalışma, yalnızca bozuk rayları tespit etmekle birlikte deray anının tespiti için yetersiz kalmaktadır.

Massimo Macucci, Stefano Di Pascoli ve Paolo Marconcini yaptıkları çalışmada kablosuz algılayıcı ağları yardımı ile veri toplayarak derayı tespit etmeyi denemişlerdir. Buna göre yük vagonları üzerine yerleştirdikleri algılayıcılar ile deray olayı tespit edilmesi ve lokomotif kabini içerisine bir uyarım gönderilmesi hedeflenmiştir. Bunun için 2 adet algılayıcı (LIS3DH ve ADXL362) ve haberleşme protokolü kullanarak bir prototip geliştirmişlerdir. Bu çalışma daha çok, seyrüsefer anında meydana gelen titreşimler üzerinden enerji toplama üzerine odaklanmıştır. Çalışma içerisinde derayın tespit edilmesi, bilginin makiniste ulaştırılmasına dair hiçbir bilgi bulunmamakla birlikte, çalışma içerisinde sunulan veriler daha çok düşük genlikli titreşimlerin toplanması ve toplam güç tüketimi analizi üzerinedir [22]. Yazarların yaptıkları çalışmada en büyük eksiklik, dönme esnasında eğimli yollarda belirlenen referans eşik değerleri değişebileceğinden, tren deray olmasa bile deray bilgisine ulaşılabileceğidir. Oysaki sunulan projede bu durum ivme, titreşim ve manyetik algılayıcıların bir arada kullanılması ile deray anının hatasız olarak tespit edilmesini sağlayabilmektedir.

Sunulan kavramsal tasarım modelinde ise literatürden farklı olarak kullanılacak algılayıcılar yardımı ile deray durumunun makinist tarafından anında fark edilmesini sağlamaya yönelik milli ve yerli bir uyarım sisteminin tasarlanması ve gerçekleştirilmesi amaçlanmıştır. Böylece deray sebebi ile meydana gelen maddi manevi kayıpların mümkün olduğunca azaltılabilmesi için vagonun raydan çıkma anının hızlı bir şekilde tespit edilip, makinistin trenin yavaşlatılması yönünde hareket etmesini sağlayacak bir uyarım sistemi ortaya çıkacaktır. Bu kapsamda kazaları önleyebilecek bir sistemin (insan unsurunu tamamen ortadan kaldırıp, hata riskini en aza indiren, tamamen otomatik bir deray tespit ve tren fren sistemine müdahale sistemi) hayat geçirilmesi düşünülmektedir.

\section{Metot}

Ray-tekerlek temas yüzeyinin pürüzlülüğü, sürtünme katsayıs1, temas açısı, temas kuvvetlerinin bileşenlerinin oranı gibi parametreler trenin deray olmasına sebep olabilen önemli parametrelerdendir. Temas bileşenlerinin oranı ile ilgili kriteri ilk olarak Nadal ortaya atmıştır ve bu kriter hala tüm dünyada kullanılan en yaygın deray belirleme parametresidir. Eşitlik (1)'de Nadal denklemi verilmiştir.

$$
\frac{Q}{P}=\frac{N \tan \alpha-\mu}{1+\mu \tan \alpha}
$$

Burada; Q; raya etki eden yatay kuvveti, $\mathrm{P}$; raya etki eden düşey kuvveti, $\mathrm{Q} / \mathrm{P}$ oranı; deray katsayısı, N; tepki kuvveti olarak tekerleğe etki eden kuvvet, $\mu$; sürtünme katsayısı ve $\alpha$ ise budenin konik eğim açısı (flanş açısı) olarak adlandırılır. Bir raylı taşıt seyir halinde iken tekerleğin temas noktalarına uygulanan kuvvetler ve buna bağlı Nadal parametreleri Şekil 2'de 
gösterilmiştir. Burada gösterilen 'fy', yanal sürtünme kuvveti olup deraya sebep olan en önemli parametredir [23].

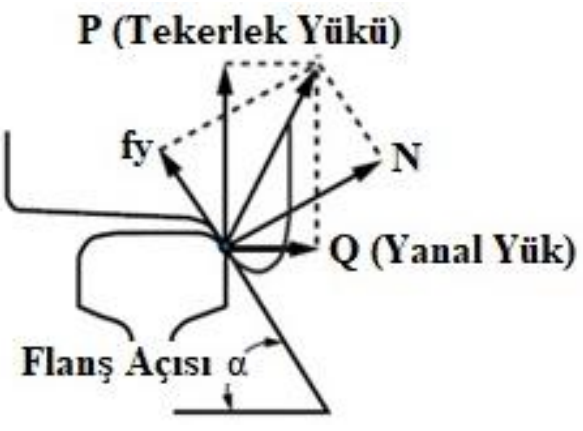

Şekil 2. Ray-teker temas noktası kuvvetleri [24]

Nadal denklemine göre birçok ülke kendi deray limit katsayısını çıkarmış olmasına rağmen (Japonya:Q/P= 0,8, Batı Avrupa:Q/P $<0,8$, Kuzey Amerika:Q/P $\leq 1 \Delta \mathrm{P} / \mathrm{Po}<0,9$, Çin: $\mathrm{Q} / \mathrm{P}=1$ ) Türkiye'de demiryolları şartnamelerinde deray için limit bir değer belirtilmemiştir [25].

Nadal formülü, tren tekerlek flanşının maksimum temas açısına bağlıdır ve bunun için kabul edilebilir bir $(\mathrm{Q} / \mathrm{P})$ limit değerinin belirlenmesi oldukça zordur. $\mathrm{Bu}$ yüzden, daha etkili yöntemler geliştirilerek, tren raydan çıkmasını doğru bir şekilde öngörebilecek modeller geliştirilmesine ihtiyaç vardır. Şekil 3'de yer değişimine bağlı raydan çıkma durumu gösterilmektedir.

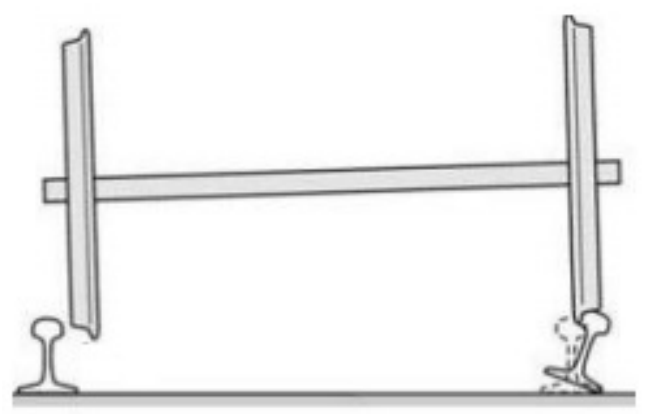

Şekil 3. Yer değiştirme sebebine bağlı deray oluşumu [26]

Nadal ve Weinstock kriterleri kimi zaman raydan çıkma olayının kestirilmesinde yetersiz kalabilmektedir. Buna karşılık, birincil yanal süspansiyon kuvvet kriteri meydana gelen raydan çıkma noktasının kestirilmesinde etkilidir. Bu yüzden demiryolu araçlarının, kararlılık ve dinamikleri üzerinde çalışılmasını sağlayacak yeni metotlar geliştirmeye ihtiyaç vardır. Raydan çıkma başlangıc1, temas düzlemi açısı, mümkün maksimum değere ulaştığı zaman gerçekleşir. Dolayısıyla hem raydan çıkma oranı, hem de ilgili süreler için raydan çıkma kriteri göz önüne alınmalidir [27].

$\mathrm{Bu}$ yüzden ayrıntıları ilerleyen bölümlerde sunulan kavramsal tasarım modeli; kartezyen koordinat sistemine göre tanımlı 3 eksenli $(\mathrm{X}, \mathrm{Y}, \mathrm{Z})$ temas analizi neticesinde hem Nadal denklemi kriterlerini sağlayabilmekte hem de raydan ayrılma anlık tespiti özelliği ile literatüre farklı ve yeni bir öneri sunmaktadır. Buna göre MEMs (micro electromechanical system) tabanlı yarıiletken ivme ve titreşim algılayıcı ((ADXL345, FZ0670)) [28,29] ve endüktif algılayıcılar (Omron E2B-M12KS04-WP-B1-2M M12 PNP/NO 2M Kablolu İndüktif Algilayıc1) [30] kullanılarak tren raylarında oluşan titreşimlerin ve temasın algılanması ve buna göre elde edilen verilerin (endüktif algılayıcı ve üç eksenli XYZ ivme verileri) mikrodenetleyici (Arduino Nano) 
karar mekanizmasında kullanılarak deray durumunu tespiti ve kablosuz uyarım sisteminin tasarımı ve gerçekleştirilmesi amaçlanmaktadır.

Endüktif algılayıcı 4mm algılama mesafesine sahip olup 10-30VDC arası çalışma gerilimine ve $100 \mathrm{~mA}$ çıkış akımına sahiptir. Endüktif algılayıcılar, konumlandırıldığı çevrede manyetik bir alan oluşturmaktadır. Oluşan manyetik alana giren metal ortamdaki manyetik alanın değişmesine sebep olmaktadır. Böylece metal cisimler temas etmeden algılamaktadır. Bu çalışmada ise endüktif algılayıcı devamlı olarak tren rayını görecek şekilde konumlandırılacağından devamlı 1 bilgisini verecektir. Eğer algılayıcının oluşturduğu referans bölge içerisinde metal algılama olayı gerçekleşmez ise, yani temas kaybolmuş ise bu deray olarak kabul edilecektir.

Tasarlanan ve gerçekleştirilmesi düşünülen sisteme ait blok şema Şekil 4'de görülmektedir.

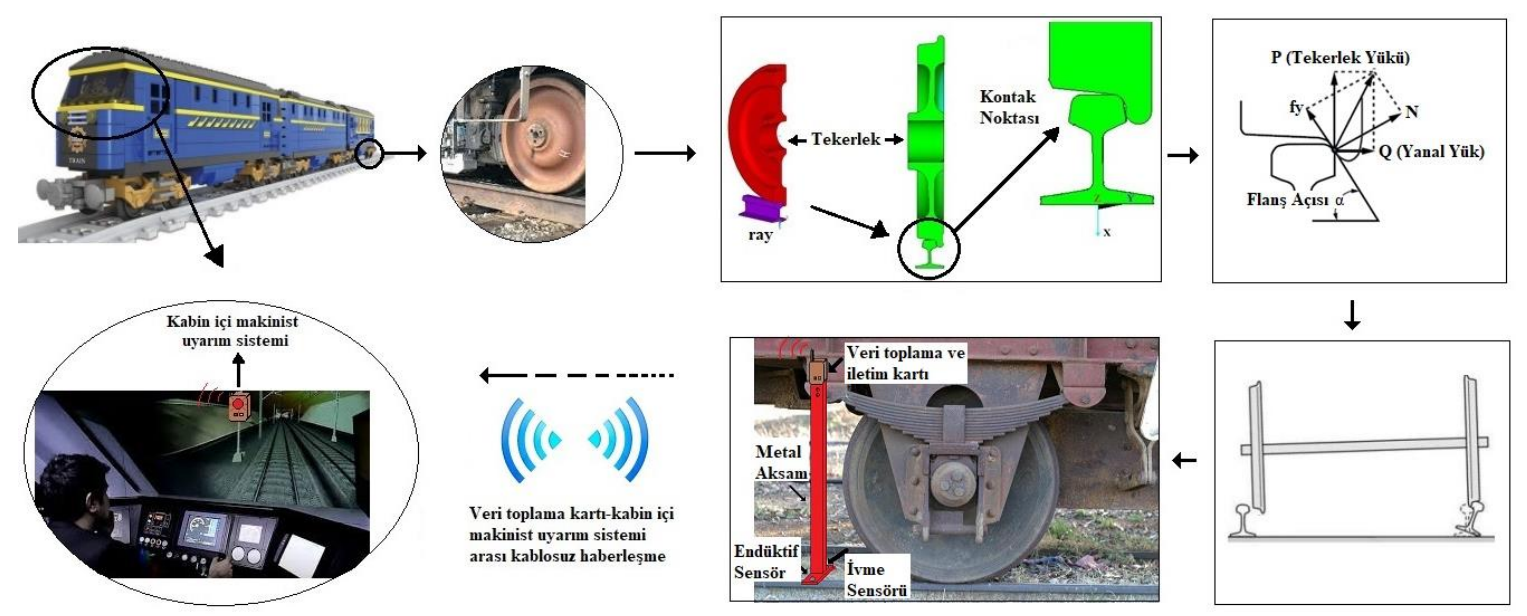

Şekil 4. Tasarlanan sisteme ait blok şema

\subsection{Veri toplama kartının oluş̧urulması}

Tasarıma göre ana kart üzerinde, çoklu haberleşme protokolüne uygun çalışabilen haberleşme sistemi, hafıza kartı, makinist için hazırlanmış ara yüzün bulunduğu ekran, sesli-1şıklı alarm sistemi, GPS (Global Positioning System-oRa/LoRaWAN Bluetooth 5.0 GPS Lcd'li RAK815$868 \mathrm{Mhz}$ Hibrit Konum İzleyici) ve GSM (Global System for Mobile Communications) SIM900B) modüllerini barındırmaktadır. Vagonlardaki algılayıcılardan bir uyarım geldiği anda, RF (radyo-frekans) modülleri aracılığı ile makinist odasında bulunan ana kart üzerindeki alarm sistemi aniden (100-200 ms gibi oldukça kısa bir gecikme değeri ile) çalışacak ve buna bağlı olarak makinist tren hızına müdahale edebilecektir. Ara yüz üzerinden hangi vagonda deray meydana geldiği bilgisini eşzamanlı görebilmesi de proje önemli hedefleri arasındadır. Böylece makinist, vagon raydan çıkmadan tren hızını düşürerek olası bir felaketin önüne geçme firsatı elde etmiş olacaktır. Tüm bu olaylara ait parametreler (ivme, vagon bilgisi, derayın olma anı (saat, dakika, saniye, gün, ay, yıl), endüktif değişimler, tren konumu vb.) ana kart üzerinde bulunan SD (secure digital) kart üzerine kaydedilecektir. Böylece yapılan seyrüsefere ait veri tabanı da oluşturulacak ve incelemeler esnasında hangi bölgedeki raylardan ne tür titreşim alındığı bilgisi ile ray geometri kusurları tespit edilerek ray durum haritası da çıkarılabilecektir. Sistem bu özelliği ile ayrı bir öneme sahip olacaktır.

\subsection{Algılayıcının tren vagonu üzerine konumlandırılması}

Ray- tekerlek teması, raylı sistemler alanında başlıca araştırma konularından biridir. Başta temas ara yüzeyi olmak üzere birçok konuda araştırma yapılmaktadır [31]. Seyrüsefer sırasında 
raylar üzerinde ilerleyen bir trenin Ray - Teker kontak ilişkisi mekaniksel olarak Şekil 4'teki blok şemada gösterildiği gibidir [32]. Tren vagonları için, üzerinde algılayıcıların bulunacağı mekanik bir aksam geliştirilecek olup, bu aksam; konik yapıya sahip olan tekerleğin raydan çıkmasını engelleyen tekerlek üzerindeki boden çıkıntısı ile rayın temas yeri olan yanakların hemen önüne, yaslanma rayına dik bir pozisyonda ve raya en yakın mesafeye yerleştirilmesi düşünülmektedir. Tasarıma göre her vagon için, vagonun her iki tarafına da bu mekanizmadan yerleştirilecektir.

\subsection{Montaj, kalibrasyon ve referans değer belirleme}

Raylardan tren geçmesi sonucu oluşan titreşimler oldukça düşük genlikli $(\mu \mathrm{V})$ ve yüksek harmonikli $(\mathrm{dB})$ sinyallerdir. Titreşimler her üç eksende hem taşıta hem de üstyapıya iletilir. Ray-teker temasına göre oluşan titreşimler Şekil 5'de görülmektedir.

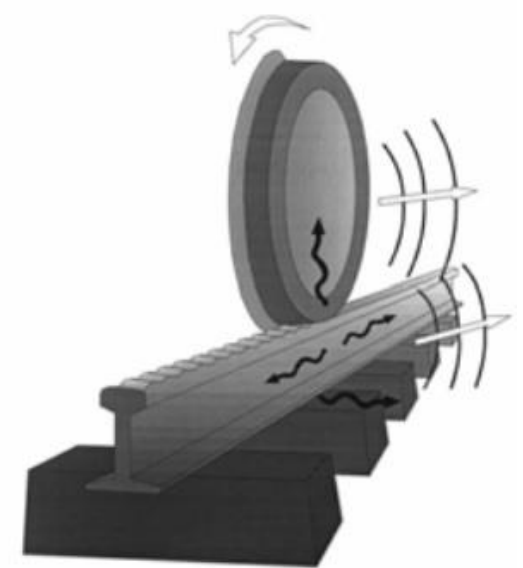

Şekil 5. Ray-tekerlek temasında titreşim iletimi [33]

$\mathrm{Bu}$ titreşimlerin işlenebilmesi için tasarlanacak yükselteç ve filtreleme devreleri ile sinyalin genliği yükseltilecek $(\mathrm{mV})$ ve istenmeyen harmonikler filtrelenecektir. Böylelikle elde edilen sinyaller mikrodenetleyicide kullanılmaya uygun hale getirilmiş olacaktır. Ayrıca çalışma kapsamında mekanik aksam üzerine konuşlandırılması hedeflenen endüktif, ivme ve titreşim algılayıcılar, analog çıkışlı olacağından ölçülen bu sinyaller yükseltildikten sonra mikrodenetleyicinin ADC (Analog-Digital Converter) girişine uygulanacak ve en uygun frekansta $(20 \mathrm{~Hz})$ örneklenerek dijitale çevrilecektir. Daha sonra, yükseltilen ve filtrelenen sinyallerin uyarım olarak kullanılabilmesi için ilgili yazılımlar (PIC C, Proteus) kullanarak bir algoritma geliştirilecektir. Algoritmaya göre, belirli bir referans seviyesinin (referans değer, sahadaki gerçek ölçümler sonucu belirlenecektir) üzerinde bir sinyal değeri ölçüldüğünde mirodenetleyici çıkışına bağlı röle aktif olacak ve kart üzerindeki RF alıcı modüle bilgi göndererek deray olayı olduğu bilgisi lokomotif içerisindeki ana karta iletilecektir. Yani algoritmadan elde edilen veriler mikrodenetleyicide değerlendirilerek RF dalgaları ile ana kart üzerinde bulunan alıcı modüle ulaşır ve burada makinist odasında bulunan alarmı (sesli ve 1şıklı ikaz) çalıştıracak komuta dönüştürür. Böylelikle alarmı duyacak olan makinist hemen duruma müdahale edebilecektir.

\section{4. Ölçümlerin ve analizlerin yapılması}

Vagonların rayların üzerinde bulunup bulunmadığı yani vagon kontrol bilgisi Mems tabanlı titreşim algılayıcılar ve endüktif algılayıcılar kullanılarak belirlenecektir. İki algılayıcı tercih edilmesinin sebebi; herhangi bir yanlış alarm durumuna firsat vermemek içindir (açı olarak eğimli yollardan geçişlerde ivme algılayıcı hatasını gidermek ve kir, toz, çamur gibi çevresel 
etkiler altında da endüktif algılayıcının yanlış bilgi vermesini engelleme adına 2 algılayıcı aynı anda kullanılarak) en doğru sonuca ulaşılması amaçlanmıştır. Tren ray yapısı gereği raylar arsındaki esneme ve genleşme amaçlı bırakılan referans boşluklar, ölçüm sırasında yanlış alarma sebep vermemesi için dikkate alınacaktır. Çünkü makiniste yanlış bilgi gittiğinde tren gereksiz yere durdurulacak ve yolcular boşuna tedirgin edilmiş olacak ve aynı zamanda zaman ve enerji kaybı da yaşanabilecektir. Bunu önlemek adına 2 algılayıcı kullanımı tercih edilmiştir. Algılayıcılardan ölçülen bilgiler bir AND (VE) kapısından geçirilecek ve ancak her iki algılayıcıdan da referans dışı bir değer ölçüldüğünde ana karta bir uyarım bilgisi iletilecektir. Böylelikle oldukça yüksek güvenirlikte bir algılama sistemi oluşturulmuş olacaktır. Bir endüktif algılayıc1, kendisine yaklaşan metal cismi temas etmeden algılamaktadır. Bu algılayıcılar her vagon için yukarıda belirtildiği noktalara, vagonların tekerlerine yakın kısımlarına monte edilerek kontrol noktasına vagonun ray üzerinde olduğu bilgisini iletecektir. Her bir vagona belirtilen algılayıcıların yanı sıra haberleşme sistemi için gerekli olan haberleşme iletim hattı, mikrodenetleyici ve beslemeler için gerekli olan güç kaynağı dönüştürücüleri de montaj edilecektir.

\section{Bulgular}

Demiryolu taşıtının seyri seferi sırasında yuvarlanma, kafa vurma ve yalpa hareketi şeklinde ortaya çıkan ve hem trene hem de raylara olumsuz etki oluşturan üç tür hareket mevcuttur. $\mathrm{Bu}$ hareketler Şekil 6'da görülmektedir.
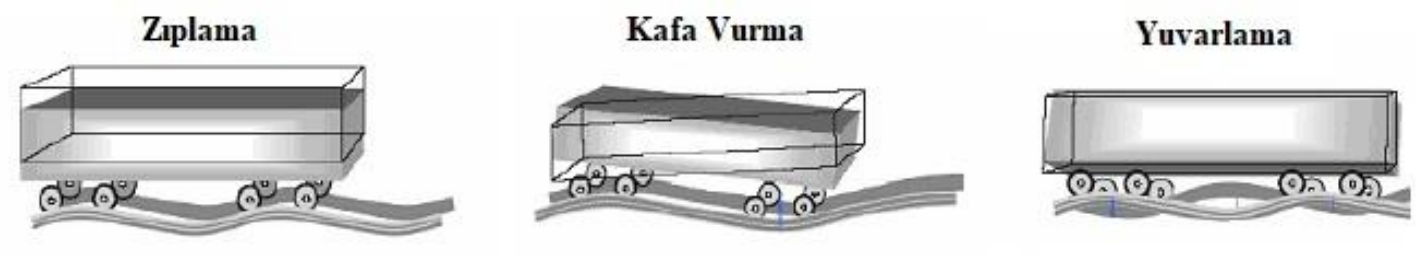

Şekil 6. Raylara olumsuz etki oluşturan hareketler [34]

$\mathrm{Bu}$ hareketler yüksek rezonans $(0-1500 \mathrm{~Hz}$ arası) değerlerine çıkabilmenin yanında daha çok rayların birleşim yerlerindeki geçişlerde (conta, kaynak geçişlerinde) meydana gelmekte ve bazen deraya da sebep olabilmektedirler. Tasarlanan sistem simülasyonunda burada bahsedilen yüksek rezonans değerleri için sinyal üreteci frekansı $1,5 \mathrm{KHz}$ 'e ayarlanmıştır. Kavramsal tasarımı gerçekleştirilen makinist uyarım sisteminin çalışabilirliğini tespit etmek üzere bir simülasyon çalışması yapılmıştır. Buna göre bir elektronik devre çizim programı (Proteus ISIS, Labcenter Electronics 7.7 SP2) yardımı ile kavramsal tasarıma ait bir devre çizilmiştir. Simüle edilen devre Şekil 7'de görülmektedir. Devre üzerinde, treni temsilen sinyal üreteci; titreşimlerin ve kapasitif değerlerin algılandığını temsil eden butonlar (endüktif algılayıcı $4 \mathrm{~mm}$ algılama mesafesine sahip olup 10-30VDC arası çalışma gerilimine ve $100 \mathrm{~mA}$ çıkış akımına sahiptir. Bu yüzden simülasyonda bu sensör +12 VDC bağlı bir buton olarak temsil edilmiştir. Çıkış dalga formu ise 0-1 arasında (temas var - temas yok) değişmektedir.), alınan sinyallerin yükseltildiği opamplı yükselteç devresi, iki algılayıcıdan da alınan verilere göre makiniste bilgi gönderilmesine karar verecek olan bir karşılaştırıcı (VE kapıs1), sinyallerin izlendiği dijital osiloskop ve deray algılandığında makinist uyarımında kullanılacak sesli/1şıklı uyarım sistemi (buzzer, led) bulunmaktadır. 


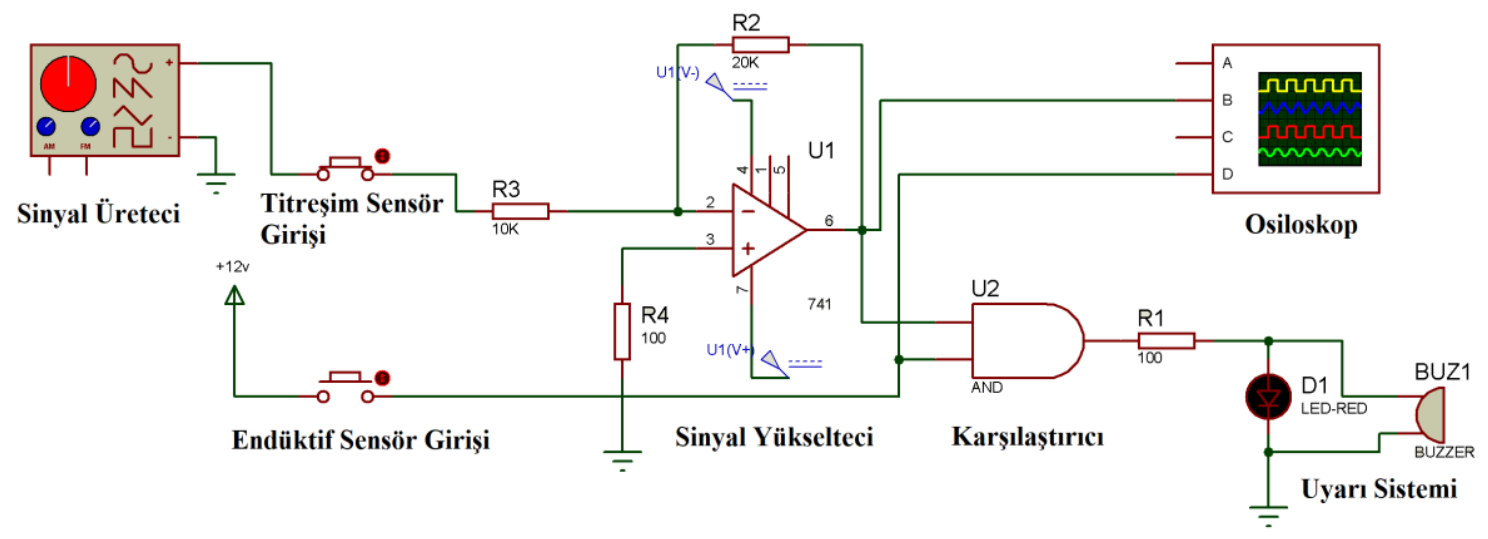

Şekil 7. Deray tespiti için hazırlanan simülasyon devresi

Demiryolu titreşimleri ve oluşan frekans aralıkları incelendiğinde, tekerlek ve ray yuvarlanma yüzeylerinde $0-1,5 \mathrm{Khz}$ aralığında bir sinyalin ortaya çıktığı, ray-tekerlek gürültüsünün ise 0$5 \mathrm{KHz}$ aralığında olduğu görülmüş̧ür [35]. Şekil 7'de verilen simülasyon devresinde sinyal üreteci frekans1 $1,5 \mathrm{KHz}$ ve genliği ise $5 \mathrm{v}$ üçgen dalga DC şeklinde ayarlanmıştır. Eşik değer olarak 2.5v seçilmiştir. Buna göre elde edilen çıkış sinyali Şekil 8'de görülmektedir. Şekil 8 dikkatle incelendiğinde karşılaştıııcı çıkışındaki değer, her iki algılayıcıdan da bilgi alındığı anda aktif olmuştur. $\mathrm{Bu}$ sinyal, makinisti sesli ve 1şıklı uyarımda bulunacak sinyaldir. Simülasyona göre deray olay1 $300 \mathrm{~ms}$ sürmüş ve 1/3 saniye gibi kısa bir sürede bu olay tespit edilerek çıkış birimleri aktif edilmiştir.

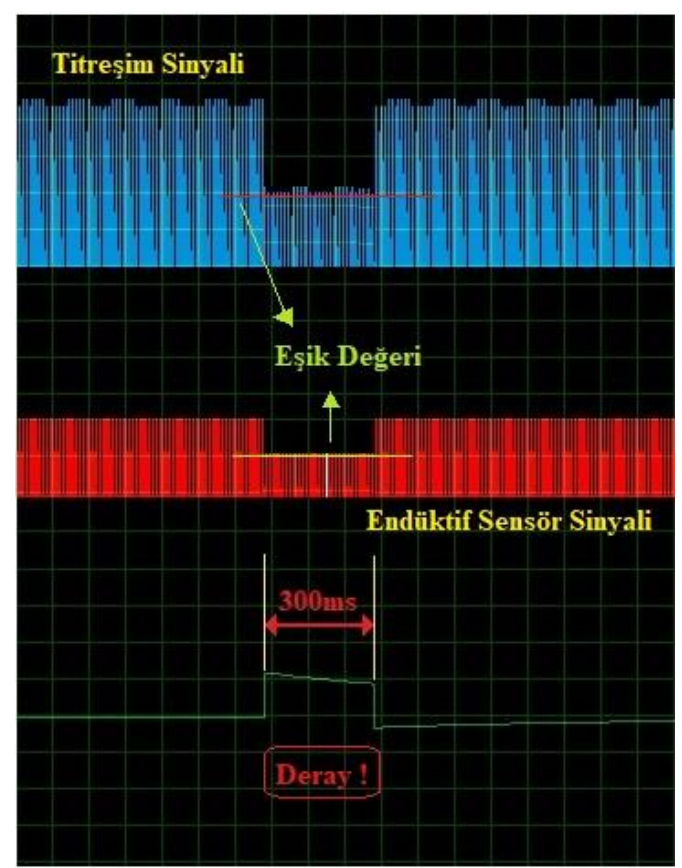

Şekil 8. Algılayıcı sinyalleri ve deray tespiti

\section{Sonuç}

Temas mekaniğinin konusu olan tekerlek-ray teması 19. yüzyılın ortalarından bu yana üzerinde yoğun bir şekilde çalışılan çok önemli bir konudur. Tekerlek-ray temasını konusu üzerinde literatürde çok sayıda çalışma ve model mevcuttur. Buna rağmen deray kaynaklı tren kazaları maalesef günümüzde devam etmektedir. $\mathrm{Bu}$ durum bu alanda yeni, farklı ve daha pratik çalışmaların yapılması gerekliliğini ortaya koymaktadır. Bunun yanında taşıt dinamiği 
simülasyonlarında yanlış cevaba ulaşmak ta oldukça olasıdır. Yapılan bu çalışmada deray olayını tekerlek-ray kontak noktasına yerleştirilmiş sensörler yardımı ile tespiti ve buna bağlı olarak ta makinist bilgilendirme sistemi geliştirilmiştir. Sonuç olarak bu çalışmada, demiryollarında güvenli yolculuk için deray anını tespit ederek makiniste bilgi veren bir sistemin kavramsal tasarımı gerçekleştirilmiş olup sistem aynı zamanda bir bilgisayar programı ile de simüle edilmiştir. Simülasyon sonuçlarına göre önerilen kavramsal modelin gerçek hayatta başarılı bir şekilde kullanılabileceği ve böylece deray kaynaklı tren kazalarının önüne geçebileceği öngörülmüştür. Bunun neticesi olarak da ölümlü / yaralanmalı / maddi kayıplı kazaların engellenerek ülkemize tren ile emniyetli ulaşım konusunda yeni bir literatür kazandırılacağına inanılmaktadır.

İleriki çalışmalarda ise bu sistemin daha da geliştirilerek otonom hale getirilmesi planlanmaktadır. Buna göre flanş açısı ve temas durumu tespit edildiğinde tren fren mekanizması ile otonom haberleşebilen bir mekanizma geliştirilecek ve böylece insan unsuru sistemden çıkarılarak hata olma olasılı̆̆ 1 tamamen ortadan kaldırılacaktır. Böylece daha güvenli ve emniyetli bir ulaşım modeli ortaya çıkmış olacaktır.

\section{Teşekkür}

$\mathrm{Bu}$ çalışma, Ondokuz Mayıs Üniversitesi Bilimsel Araştırma Projeleri (BAP) koordinatörlüğü tarafindan PYO.YMY.1901.17.001 proje numarası ile desteklenmiştir.

\section{Kaynakça}

[1] Ulaştırma, Denizcilik ve Haberleşme Bakanlığı, "Ulaşan ve Erişen Türkiye 2017 Faaliyet Raporu," 2017. [Online]. Available: https://www.uab.gov.tr/bakanlik-yayinlari [Accessed February 05, 2021]

[2] Y. Candemir, "Küreselleşme, teknolojik gelişme ve ulaştırmada yenilikler: dünya ve Türkiye," TMMOB İnşaat Mühendisleri Odası VI. Ulaştırma Kongresi, İstanbul, Türkiye, 2005, pp. 13-29

[3] TCDD AR-GE Dairesi Başkanlığı, "Emniyet Yönetim El Kitabı," 2017. [Online]. Available: https://www.tcdd.gov.tr/files/pdf/eyskitap.pdf [Accessed February 05, 2021]

[4] B. T. Kayaalp, "Demiryolu araçlarının testlerinde kullanılan laboratuvar ekipmanları: ray simülatörleri," Demiryolu Mühendisliği, no. 11, pp. 41-51, Jan. 2020

[5] TCDD İşletmesi Genel Müdürlüğü, "2009 Yılı Sektör Raporu," 2009. [Online]. Available: https://www.tcdd.gov.tr/files/istatistik/2009sektorraporu.pdf [Accessed February 05, 2021]

[6] T.C. Ulaştırma Bakanlığı, "Ulaştırma ve Haberleşme Terimleri Sözlüğü,” 2011. [Online]. Available: https://www.uab.gov.tr/uploads/pages/kutuphane/a9ed7795d6e394d-5ea04166a902a.pdf [Accessed February 05, 2021]

[7] H. Güler, S. Jovanovic, "Demiryollarında hız yükseltilmesi amacıyla yapılması gerekli ön çalışmalar," 6. Ulaştırma Kongresi, Bildiriler kitabl, İstanbul, Türkiye, 2005, pp. 275-298

[8] TCDD Strateji Geliştirme Dairesi Başkanlığı İstatistik ve Analiz Şubesi, "Demiryolları İstatistik Y1llı̆̆12012-2016,” 2017.2 [Online]. Available: https://www.tcdd.gov.tr/files/istatistik//20122016yillik.pdf [Accessed February 05, 2021]

[9] Ö. Akbayır, "Dünya'da ve Türkiye'de demiryolu kazaları nedeniyle meydana gelen ölüm oranlarının karşılaştırılması," Demiryolu Mühendisliği, vol. 5, pp. 45-52, Haz. 2017

[10] Ulaştırma, Denizcilik ve Haberleşme Bakanlı̆̆ı, Kaza Araştırma ve İnceleme Kurulu, "2017 Yı1ı Demiryolları Kaza İstatistikleri Kitapçı̆̆1," 2017. [Online]. Available: https://ulasimemniyeti.uab.gov.tr/uploads/pages/istatistikler/20180208-155359-76347-1-64.pdf [Accessed February 05, 2021]

[11]Ç. Tabak, "Demiryollarındaki kaza istatistikleri veritabanı, risk azaltma yöntemleri, alınan önlemler ve Avrupa'daki örneklerinin kıyaslanması," Ulaştırma ve Haberleşme Uzmanlığı Tezi, Ulaştırma, Denizcilik ve Haberleşme Bakanlığı, Ankara, Türkiye, 2014

[12]Ulaştırma, Denizcilik ve Haberleşme Bakanlığı, Kaza Araştırma ve İnceleme Kurulu, "Kaza İnceleme Raporu,” $2017 . \quad$ [Online]. Available: https://ulasimemniyeti.uab.gov.tr/uploads/pages/demiryolu/izmir.pdf [Accessed February 05, 2021] 
[13] Ulaştırma, Denizcilik ve Haberleşme Bakanlığı, Kaza Araştırma ve İnceleme Kurulu, "Kaza İnceleme Raporu," $2018 . \quad$ [Online]. Available: https://ulasimemniyeti.uab.gov.tr/uploads/pages/demiryolu/elazig.pdf [Accessed February 05, 2021]

[14] A. Yılmaz, "Demiryolu üstyapısında balast kirliliği," Mehmet Akif Ersoy Üniversitesi Fen Bilimleri Enstitüsü Dergisi, vol. 6, no:1, pp. 11-17, Aralık 2015

[15] Millî Eğitim Bakanlığı Raylı Sistemler Teknolojisi, "Raylı sistem araçlarının kumanda ve kontrol devreleri," 2013. [Online]. Available: https://docplayer.biz.tr/2338708-T-c-milli-egitim-bakanligirayli-sistemler-teknolojisi-rayli-sistem-araclarinin-yardimci-devre-elektrik-sistemleri.html [Accessed February 05, 2021]

[16] S. Miura, H. Takai, M. Uchida, Y. Fukada, "The mechanism of railway tracks," Japan Railway \& Transport Review (JRTR), vol. 15, pp. 38-45, Mar. 1998

[17] A. Erel, S. Dündar, "Derayman olaylarının muhtelif nedenleri ve derayman riskini azaltmak için alınacak önlemler," 6. Ulaştırma Kongresi, İstanbul, Türkiye, 2005

[18] Ö. Kepenek, N. Karaboğa, "Demiryolu ulaşımında vagon kontrol sistemi," in Otomatik Kontrol Ulusal Toplantısl, TOK2013, Malatya, Türkiye, 2013, pp. 1253-125

[19]"Tren Gözlem Sistemi" Nov., 2020. [Online]. Available: http://www.lojiport.com/news_detail.php?id=9599 [Accessed November 05, 2020]

[20]B. Aydemir, Y. Akgül, E. Tolay, "Demiryolu uygulamalarında vagonların yük ve güvenlik kontrolünün izlenmesi," International Iron \& Steel Symposium, Karabük, Türkiye, 2012

[21] G. Karaduman, M. Karaköse, E. Akın, "Ray arızalarının teşhisi için deneysel bir yaklaşım," in Otomatik Kontrol Ulusal Toplantısl, TOK2013, Malatya, Türkiye, 2013, ss:1350 -1355

[22] M. Macucci, S. Di Pascoli, P. Marconcini and B. Tellini, "Derailment detection and data collection in freight trains, based on a wireless sensor network," IEEE Transactions on Instrumentation and Measurement, vol. 65, no. 9, pp. 1977-1987, Sept. 2016, doi: 10.1109/TIM.2016.2556925.

[23] C. Arslan, "Raylı taşıtlarda bakım planlaması, deray şartları ve emniyet değerlendirmesi," Yüksek Lisans tezi, Makina Mühendisliği Anabilim Dalı, İstanbul Teknik Üniversitesi, İstanbul, Türkiye, 2011

[24] O. Kiyoshi, "Research and developlment for eliminating wheelclimb derailment accidents," JR East Technical Review, vol. 2, pp. 46-50, 2002

[25] M. V. Taciroğlu, "Derayman nedenlerinin araştırılması ve nadal kuramı," Yüksek Lisans tezi, İnşaat Mühendisliği Anabilim Dalı, Süleyman Demirel Üniversitesi, Isparta, Türkiye, 2008

[26]Ç. Uyulan, "Demiryolu araçları için yeniden tutunma kontrolünün ve kararlılık analizlerinin yapılması,” Doktora tezi, Mekatronik Mühendisliği Anabilim Dalı, İstanbul Teknik Üniversitesi, İstanbul, Türkiye, 2017

[27]L. M. Sweet, R. A. Budell, A. Karmel, D. Lassman, and D. Schulte, "Theory and measurement of derailment quotients," Vehicle System Dynamics, vol. 12, no. 1-3, pp. 177-178, Jul 2007 , doi.org/10.1080/00423118308968752

[28] A. Böğrek, H. Sümbül, "Development of driver analysis system to improve driving comfort and to reduce mechanical abrasion in vehicles," The Journal Of Technical Science, vol. 9, no. 3, pp. 9-14, Nov. 2019, doi:10.35354/tbed.509560

[29]H. Sümbül, and A. Böğrek, "Development of the road analysis system to provide the fuel efficiency awareness in the vehicles," Bilge International Journal of Science and Technology Research, vol. 1, no. 1, pp. 6-9, Nov. 2017

[30] Inductive Sensor, "Omron Silindir Endüktif Sensör," 2021. [Online]. Available: https://tr.rsdelivers.com/product/omron/e2b-m12ks04-wp-b1-2m/omron-m12-x-1-inductive-sensorbarrel-pnp-no/8052567 [Accessed February 5, 2021].

[31]Y. Özdemir, "Ray-teker temasında temas parametrelerinin incelenmesi," Demiryolu Mühendisliği, vol. 11, pp. 1-13, Oca. 2020

[32] M. A. Arslan, "Ray teker kontak ilişkisi analizi," Araştırma Projesi, Tasarım ve İmalat Mühendisliği Anabilim Dalı, Gebze Yüksek Teknoloji Enstitüsü, İstanbul, Türkiye, 2008

[33] V. Arlı, "Demiryolu titreşimlerinin model hat üzerinde çok yönlü analizi," Doktora tezi, Fen Bilimleri Enstitüsü, İstanbul Teknik Üniversitesi, İstanbul, Türkiye, 2009 
[34]M. Bayraktar, "Raylı taşıtların dingillerinin dinamik analizi," Doktora tezi, Makine Mühendisliği Anabilim Dalı, Yıldız Teknik Üniversitesi, İstanbul, Türkiye, 2010

[35] K. Knothe, Gleisdynamik. Ernst\&Sohn, Berlin, Germany, 2001

\section{Özgeçmiş}
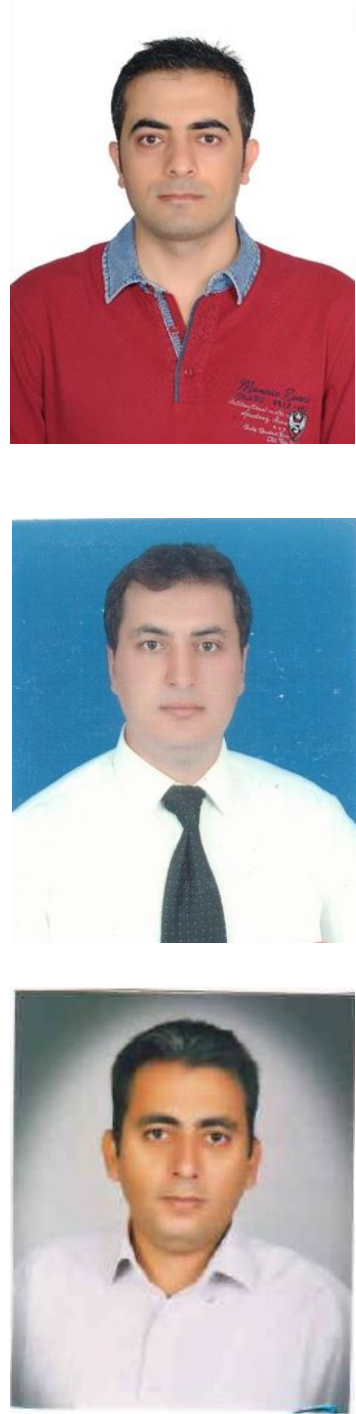

\section{Harun SÜMBÜL}

1984 Sivas doğumludur. Cumhuriyet üniversitesi Elektrik-Elektronik Mühendisliği(EEM) Lisans, Selçuk Üniversitesi EEM Y.Lisans ve Karabük Üniversitesi EEM Doktora derecelerine sahiptir. Gümüşhane Üniversitesi EEM Arş. Gör. ve Ondokuz Mayıs Üniversitesi Yeşilyurt Demir Çelik MYO`da Öğr. Gör. olarak çalışmış ve halen burada görevine Dr. Öğretim Görevlisi olarak devam etmektedir. İlgi alanları; sinyal işleme, elektromekanik sistemler, kontrol sistemleri üzerinedir. Dr. Sümbül, iyi derecede İngilizce bilmekte olup evli ve 2 çocuk babasidir.

E-Posta: harun.sumbul@omu.edu.tr

\section{Ahmet BÖĞREK}

1983 Tokat Niksar doğumludur. Liseyi 2000 yılında Tokat Endüstri Meslek Lisesi'nde, lisans eğitimini Selçuk Üniversitesi Teknik Eğitim Fakültesi Otomotiv Öğretmenliğinde, y. lisans eğitimini ise Selçuk Üniversitesinde tamamlamıştır. 2005 yılından itibaren çeşitli özel kuruluşlarda çalışmıştır. 2011 yılında Ondokuz Mayıs Üniversitesi Yeşilyurt Demir Çelik MYO otomotiv teknolojisi bölümünde öğretim görevlisi olarak başlamış ve halen görevini sürdürmektedir. Sakarya Uygulamalı Bilimler Üniversitesinde doktora eğitimine devam etmektedir. İlgi alanları; mekanik sistemler, katı modelleme, enerji

E-Posta: ahmet.bogrek@omu.edu.tr

\section{Abdurrahman TUNÇER}

1978 yılında Sivas'ta doğdu. Lisans eğitimini 1997-2001 Gazi Üniversitesi Teknik Eğitim Fakültesi Elektrik Bölümünde tamamladi. 2004-2015 yılları arasında Sivas Demir Çelik fabrikasında (Sidemir A.Ş.) teknik yöneticilik yaptı. 2019 yılında Cumhuriyet Üniversitesi Optik Mühendisliğinde yüksek lisans eğitimini tamamladı. 2015 yılından itibaren Ondokuz Mayıs Üniversitesi Yeşilyurt Demir Çelik Meslek Yüksekokulu'nda öğretim görevlisi olarak çalışmaktadır. İlgi alanları, haberleşme, sinyalizasyon, elektrik güç devreleri.

E-Posta: abdurrahman.tuncer@omu.edu.tr

\section{Beyanlar:}

Bu makalede bilimsel araştırma ve yayın etiğine uyulmuştur.

Tüm yazarların eşit oranda katkısı olmuştur. 